\title{
EVOLUTION OF EPHEMERIDES REPRESENTATION AND DIFFUSION
}

\author{
P.K.SEIDELMANN \\ U.S.Naval Observatory
}

\begin{abstract}
There has been, and continues to be, a close interaction between celestial mechanics used for the generation of ephemerides, mathematical techniques, and computer technology. As the computer capabilities of the ephemerides offices and the users of ephemerides have improved, the methods of determining and the accuracies of ephemerides have changed and the medium and representation of the ephemerides provided to the user have evolved.

Ephemerides have been provided in the form of theories, tables, tabulations, polynomials, graphics, and subroutines by means of the printed page, punched cards, magnetic tape, floppy disks, CD/ROMs, and electronic mail. As mathematical techniques and computer technology continue to develop and the requirements for ephemerides evolve, the methods of representing and diffusing ephemerides will continue to improve.
\end{abstract}

\section{Introduction}

The evolution of ephemerides representation and diffusion can be tied to the technological and cultural developments over the years. In the latter years, technological development has been mostly the development of computer technology, including the speed, size, and memory capabilities of the computer and the media used for storage of computer data. In many cases, the changes that have taken place in ephemerides can be tied to people and dates, when significant changes in procedure were introduced. In parallel, the changes of ephemerides can be tied to scientific developments that required changes, or observations that differed from the ephemerides and thus required scientific developments.

The paper will cover the early years of ephemerides, the development period as ephemerides representation and diffusion flourished, and then 
TABLE 1. Early Ephemerides

\begin{tabular}{ll}
\hline DATES & PREPRINTING \\
\hline $3000-2000 \mathrm{BC}$ & Stonehenge (equinoxes, solstices) \\
$700-100 \mathrm{BC}$ & Linear zigzag functions (eclipses, lunar crescent visibility) \\
$200 \mathrm{BC}$ & Apollonius-Planetary motion (eccentric and epicyclic motion) \\
$200 \mathrm{BC}$ & Hipparchus-star catalog-precession \\
& Numerical values in geometric models \\
$200 \mathrm{AD}$ & Ptolemy-" Almagest"-" Handy Tables" \\
$800 \mathrm{AD}$ & Venerable Bede-computers-Easter from lunar solar cycles \\
$900 \mathrm{AD}$ & al-Khworizmi "Zij"-lunar crescent-astrology \\
$900 \mathrm{AD}$ & al-Battani "Zij"-sines replace chords \\
$1000 \mathrm{AD}$ & Toledan Tables \\
$1200 \mathrm{AD}$ & Roger Bacon-Easter and astronomy differences \\
$1252(1320)$ & "Alfonsine Tables" (Paris or Castile?) \\
1474 & Johann Muller "Regiomontanus" \\
1496 & Abraham Zactus "Almanach Prepetuum" \\
1500 & Almanacs - configurations, Tables (Phases of Moon, \\
1545 & Transits of planets rising \& settings, wit and wisdom) \\
1550 & Copernicus "De Revolutionibus" tables \\
1600 & Erasmus Reinhold's "Prutenic Tables" \\
1627 & John Tapp "Seaman's Kalendar" (Sun, Moon, bright \\
1676 & stars for seamen) \\
& Kepler "Rudolphine Tables" (elliptic orbits, \\
& parameters from Tycho) \\
& Mariners New Calendar \\
\hline
\end{tabular}

the computer period when diffusion techniques were driven by computer technology. Finally, conclusions and expectations for future development of ephemerides are considered.

In this paper, I will define an ephemeris as a communication of a predicted astronomical event. This definition allows the consideration of oral tradition which does not survive forever, but is sophisticated and enduring. There is also the question of the purpose of ephemerides, and we will touch on some of these different purposes as we trace their history. Cultural requirements, calendars, religion, navigation, and scientific interests have been involved, and also astrology has been a consideration throughout the whole period.

\section{Early Years}

The earliest representations of ephemerides (Table 1) that survive to this day are the standing stones as exemplified by Stonehenge, which provides information on the equinoxes and solstices, and dates back to 2000 to 3000 
TABLE 2. Ephemerides and Scientific Developments

\begin{tabular}{lll}
\hline Date & Person & Scientific Development \\
\hline 350 BC & Aristotle & Geocentric universe \\
200 BC & Apollonius & Epicycle, eccentric motion \\
200 BC & Hipparchus & Precession \\
200 AD & Ptolemy & Mathematical astronomy \\
1545 & Copernicus & Sun-centered solar system \\
$1609-19$ & Kepler & Laws of motion \\
1687 & Newton & Universal law of gravity \\
1750 & Mayer & Lunar Tables \\
1772 & Euler & Lunar Tables \\
1772 & Lagrange & Libration points \\
1784 & Laplace & Solar system stability \\
1801 & Gauss & Orbit determination \\
1835 & Hamilton & Generating functions, quaternions \\
1846 & LeVerrier,Adams & Discovery of Neptune \\
1860 & LeVerrier & Planetary theories \\
1878 & Hill & Lunar equations of motion \\
1900 & Newcomb & Astronomical standards, planetary theories \\
1919 & Einstein & Theory of relativity \\
1927 & DeSitter & Variation in Earth rotation \\
1930 & Brown & Lunar theory \\
1958 & Brouwer,Vinti & \\
& Kozai, Garfinkel & Artificial satellite theory \\
1960 & Danjon, Clemence & Ephemeris Time \\
\hline
\end{tabular}

BC. Usually Aristotle is credited with the concept of the geocentric universe, and Apollonius with the introduction of eccentric and epicycle circular motions to provide planetary motions. Based on the construction of a star catalog in the second century BC, Hipparchus was able to detect precession and he was also able to apply numerical values to the parameters in the geometric planetary models. In $200 \mathrm{AD}$, Ptolemy developed mathematical astronomy in his "Almagest." Then, his "Handy Tables" enabled one to calculate celestial longitude and latitude of the Sun, Moon, and planets and the phenomena for different terrestrial latitude regions. In the eighth century, the Venerable Bede was concerned with the calculation of the date of Easter based on solar/lunar cycles of various degrees of accuracy. In the Middle Ages, Ptolemy was followed by the Islamic astronomers who were interested in the visibility of the lunar crescent for Islamic calendar purposes. They also were, of course, interested in astrology. al-Khwarizmu produced the first major Islamic tables, "Zij," in the ninth century. The Alfonsine Tables were introduced in the thirteenth century. Their origin is 
uncertain, either being the court of Alphonso X in Castile or in Paris. The Copernicus tables in "De Revolutionibus" of 1543 were difficult to use. But Erasmus Reinhold's "Prutenic Tables" made the methods of Copernicus more accessible to almanac makers until the Rodolphine tables of Kepler, which were based on elliptic orbits and parameters from Tycho.

In about 1500 the printing press became available and almanacs became popular. These almanacs included configurations of the planets, phases of the Moon, transits of the planets, times of risings and settings and, in addition, some wit and wisdom.

The reasons for ephemerides and their diffusion developed over the years: scientific curiosity, the cultural reasons of calendar and religious dating, seasons, agricultural purposes, and, of course, astrological thoughts. Ephemerides became paramount for purposes of navigation and the determination of time.

In the 1600 s, the Seaman's Calendar became available containing the positions of the Sun, Moon, and bright stars for sailors. During this period of introduction of the methods of printing and presenting ephemerides, there was a corresponding process of scientific development (Table 2) which included the Sun-centered solar system of Copernicus, the laws of motion of Kepler, the Universal law of gravity of Newton, and lunar tables of Euler.

The situation with regard to ephemerides, computing, and scientific development was addressed in the seventeenth century by Leibniz who wrote "Also the astronomers surely will not have to continue to exercise the patience which is required for computation. It is this that deters them from computing or correcting tables, from the construction of Ephemerides, from working on hypotheses, and from discussions of observations with each other. For it is unworthy of excellent men to lose hours like slaves in the labor of calculation which could safely be relegated to anyone else if machines were used."

The foundations of celestial mechanics include the concepts of libration points by Lagrange, the question of solar system stability by Laplace, the orbit determination method necessitated by discoveries of the minor planets as developed by Gauss, and the generating function and quaternions developed by Hamilton. A primary scientific discovery based on ephemerides was the accurate prediction of Neptune by LeVerrier and Adams. Planetary and lunar theories were developed by LeVerrier and Newcomb which, based on their accuracy levels and those of the observations, led to the requirement for the theory of relativity by Einstein, and the recognition that the rotation of the Earth was variable by de Sitter. 
TABLE 3. Examples of National Almanacs (Navigation \& Astronomy)

\begin{tabular}{ll}
\hline 1679 & $\begin{array}{l}\text { Connaissance des Temps (France) } \\
\text { (French Academy; Bureau des Longitudes) }\end{array}$ \\
1767 & Nautical Almanac and Astronomical Ephemeris (UK) \\
1776 & $\begin{array}{l}\text { Berliner Astronomisches Jahrbuch (Germany) } \\
\text { Nautisches Jahrbuch }\end{array}$ \\
1791 & Efemerides Astronomicas (Spain). Almanaque Nautico \\
1855 & The American Ephemeris and Nautical Almanac (USA) \\
1923 & Annuaire Astronomique (USSR) \\
1933,1941 & American Air Almanac (USA) \\
1937 & British Air Almanac (UK) \\
1943 & Japanese Ephemeris (Japan) \\
1958 & Indian Ephemeris and Nautical Almanac (India) \\
1975 & Almanac for Computers (USA) \\
1982 & Floppy Almanac \\
1993 & Multiyear Interactive Computer Almanac (MICA) \\
1994 & Redshift \\
\hline
\end{tabular}

TABLE 4. Ephemerides Accuracy Values

\begin{tabular}{llll}
\hline Date & Purpose & \multicolumn{2}{c}{ Accuracy } \\
\hline BC & Eclipse prediction & $30 ”$ & \\
1750 & Navigation & 1 ” & \\
1900 & Scientific investigation (masses) & $1 ”$ & \\
1960 & Dynamical reference frame & $0 . ” 1$ & \\
1965 & Space mission & $0 . ” 01$ & Moon $10 \mathrm{~km}$ \\
1990 & Dynamical reference frame & $0 . ” 001$ & Moon $1 \mathrm{~cm}$ \\
\hline
\end{tabular}

\section{Development Period.}

In the development of ephemerides, there arose the need for almanacs for navigation and astronomy. Thus, the Connaissance des Temps from France in 1679 became the first of the national almanacs. It predates the Bureau des Longitudes, whose bicentennial we celebrate at this meeting. Other countries followed with astronomical and navigational publications (Table 3). There arose from the national ephemerides and almanacs, the need for international standardization which led to the establishment of a standard meridian, standard time, standard astronomical constants, a single reference frame, and the beginnings of a general method of international cooperation. During the course of this time, there was also a continuing progress in the accuracy of ephemerides (Table 4). This progress is tied to the scientific developments which were either driven by the accuracy requirements or made possible the improvements in accuracies. 
TABLE 5. Ephemerides Dissemination Techniques

\begin{tabular}{llll}
\hline Date & Method & New Technology & Technique \\
\hline $2000 \mathrm{BC}$ & standing stones & alignments & observations \\
$700 \mathrm{BC}$ & tablets & clay & tables \\
$200 \mathrm{BC}$ & scribes & paper & tables \\
1500 & book & printing press & tables, graphs \\
1900 & books & photographs & theories \\
1940 & punched cards & punched cards & tables \\
1960 & magnetic tapes & computers & tabular \\
1965 & magnetic tapes & computers & theories \\
1975 & printed & hand calculators & Chebychev series \\
1982 & floppy disks & personal computers & programs \\
1990 & CD/ROM & compact disks & graphics, images \\
1994 & electronic & networks & tables, graphics, \\
& & & images, programs \\
\hline
\end{tabular}

TABLE 6. Computers for Ephemerides

\begin{tabular}{lllll}
\hline Date & Place & Person & Equipment & Purpose \\
\hline 1623 & Tubingen & Schickard & desk calculator & \\
1642 & France & Pascal & adding machine & \\
1693 & Mainz & Leibniz & desk calculator & \\
1822 & Cambridge & Babbage & difference integrate & \\
1854 & Sweden & Seheitz & Babbage design & planetary distances \\
1863 & Sweden & Wiberg & difference & logarithms \\
& America & Grant & difference & logorithms \\
1909 & Berlin & Hamann & difference & Peters logarithms \\
1929 & UK NAO & Comrie & printing calculator & Almanacs \\
1933 & Columbia U & Eckert & punched cards & orbit computation \\
1940 & USNO & Eckert & punched cards & Air Almanac \\
& & Clemence & & Theory of Mars \\
1947 & Cincinnati & Herget & punched cards & minor planets \\
1948 & IBM HQ & Eckert & IBM SSEC & outer planets \\
1948 & Yale U & Brouwer & punched cards & star measuring \\
1954 & & Herget & UNIVAC I & Jupiter VIII \\
1954 & Dahlgren VA & Herget & NORC & minor planets \\
\hline
\end{tabular}

\section{Computer Development and Dissemination Techniques.}

There has been a close relationship between the advancement of computers and computer technology and the methods in computing and disseminating ephemerides. In the early days, before electronic computers, tabular representations of theories were the most efficient methods for people to calculate 
ephemerides and to determine daily positions of the bodies (Table 5). With the arrival of punched cards, the application of those tables could be automated and the ephemerides more rapidly and correctly computed (Table 6). The electronic computer made the computation of special perturbations, or numerical integration, a much more attractive means of computing ephemerides, so that the IBM Selective Sequence Electronic Calculator (SSEC) was used to compute by numerical integration the ephemerides of the five outer planets. The general method of computing ephemerides became by means of numerical integration. At the present time, the only means of achieving the accuracy required for lunar laser ranging or radar ranging is by means of numerical integration.

The method of disseminating ephemerides has followed somewhat different routes. Tabular methods of providing data have existed since the technology of clay tablets. With the advent of paper and the printing process, the printing of the theories of the motions of the bodies and tables for computing ephemerides was introduced, both as a means of communicating a scientific accomplishment, and as a means for others to compute the ephemerides themselves. With the introduction of punched cards, both the ephemerides in tabular type form and the theories could be recorded in machine-readable format (1940 - 1965). This was followed by magnetic tapes, which provided a more compact, or more rapidly readable, format for providing the information (1962-1985). On magnetic tapes, data at uniformly spaced time intervals covering long periods of time could be provided so that people could interpolate for whatever time they wanted from the ephemerides.

With the introduction of the hand-held calculator (1974), there was a desire for a method whereby one could make a limited number of entries into the hand-held calculator and interpolate the data to determine celestial positions for specific times. This led to the publication of Chebychev polynomials for specific time limits, to be used with the hand-held calculator. With the advent of the personal computer (1980) came the floppy disk. Now the previously printed data could be stored on a floppy disk and accessed by a program also stored thereon. This technology let to the supplement of the printed book with a floppy disk to provide ephemeris data. The arrival of the CD ROM (1990) permitted much more data storage and led to the ability to include graphics. The availability of networks whereby people can access data from all over the world (1994), has provided a new means of disseminating the data in the forms of tables, graphs, programs, and pictures.

In the early days the data were provided in a tabular form and in graphs, or plots, of the planetary positions with respect to the stars, although I have yet to see an example of such an early plot that still exists. Then the 
capability for computing and the availability of the theories for people to calculate their own positions became desirable in the early 20th century. With the advent of computers and magnetic tapes, the tabular material was widely used on sequential storage. Now with the advent of the faster computers and more storage capability, programs based on theories, or based on compact Chebychev representation of sequential data, are more desirable than reading long sequential series of data. With the development of computer graphics and imaging capability, we now see graphics coming back as a popular augmentation to the accurate ephemerides.

\section{Conclusion}

Over the years there has been a close tie between ephemerides and cultural, scientific, and technological developments, computer technology, and individuals. There has also been, and unfortunately continues to be, a close tie between the ephemerides and astrology. It appears that a change in this progression should not be anticipated. It is my expectation that the future should see the distribution of data and information via networks, so the users (astronomers, space scientists, navigators, or the general public) can call up a graphic presentation of selectable scales showing the configurations of the planets, satellites, and stars for any time. In addition, they can call up numerical values to whatever accuracy is desired. In addition, standardized software packages will be available so that computations can be embedded in their own programs, without each individual writing all the software oneself.

\section{References}

Duncombe, R.L., Seidelmann, P.K., and Janiczek, P.M. (1974) "Planetary Ephemerides" In Highlights of Astronomy, G. Contopoulos, ed. 223-227.

Explanatory Supplement to the Astronomical Almanac, P.K. Seidelmann, ed., University Science Books, Mill Valley, California, 1992.

Gingerich, O. (1993) The Eye of Heaven Ptolemy, Copernicus, Kepler American Institute of Physics, New York.

Goldstein, B.R.(1972) "Theory and Observation in Medieval Astronomy," Isis 63, 39-47.

Hawkins, G.S. (1965) Stonehenge Decoded, Doubleday and Co., Garden City, NY.

Neugebauer, O. (1957) The Exact Sciences in Antiquity, Brown U. Press, Providence.

Pedersen, O. (1993) Early Physics and Astronomy, 2nd ed," Cambridge U. Press.

Seidelmann, P.K. (1976) "Celestial Mechanics," In Encyclopedia of Computer Technology 4., K. Belzer, A.G. Holzman and A. Kent, eds., Marcal Dekker Inc., New York.

Seidelmann, P.K. (1979) "The Ephemerides: Past, Present and Future" In Dynamics of the Solar System, R.L. Duncombe, ed., 99 - 114.

Seidelmann, P.K. (1993) "Review of Planetary and Satellite Theories," Celestial Mechanics and Dynamical Astronomy 56, 1 - 12.

Seidelmann, P.K., Janiczek, P.M., Haupt, R.F., (1976), "The Almanacs - Yesterday, Today and Tomorrow," Navigation 24 303-312.

van der Waerden, B.L. (1974) Science Awakening II; the Birth of Astronomy Oxford U. Press. 